\title{
The Effects of Using Web-Based 3D Design Environment on Spatial Visualisation and Mental Rotation Abilities of Secondary School Students
}

\author{
H. Ebru DERE ${ }^{1}$, Filiz KALELIOGLU² \\ ${ }^{1}$ Bahcesehir College Ankara $50^{\text {th }}$ Year Campus, Ankara, Turkey \\ ${ }^{2}$ Baskent University, Faculty of Education, Ankara, Turkey \\ e-mail:ebruakinturk@gmail.com,filizk@baskent.edu.tr
}

Received: January 2020

\begin{abstract}
The purpose of this study is to investigate the effects of applications created using a web-based 3D design environment on the spatial visualisation and mental rotation abilities of secondary school students. A total of 63 school students from the sixth grade participated in the study. The researchers applied a mixed research method including both quantitative and qualitative measures. The Spatial Visualisation Test, Mental Rotation Test, and Santa Barbara Solids Test, which concurrently measure spatial orientation and spatial relations, were used as tools to measure the different components of spatial ability prior to and after the treatment application. Following the treatment, a focus group interview using structured questions was conducted. A statistically significant difference showed an increase in all three test scores of the students; also, the students stated that they were satisfied with being able to design and create something new.
\end{abstract}

Keywords: spatial ability, spatial visualisation, mental rotation, 3D design.

\section{Introduction}

Technology is developing and progressing rapidly, and these developments are also reflected in the field of education and have brought significant innovation to the classroom environment. The expectations from students and teachers, which are indispensable elements of the educational environment, have also been differentiated in order for these innovations to be put into practice. The International Society for Technology in Education (ISTE) set standards defined as the "National Educational Technology Standard for Teachers" (NETS-T) and the "National Educational Technology Standard for Students" (NETS-S). Among the recommended standards for both teachers and students is the ability and skillset required to utilise technology for the purposes of learning and teaching, to be able to demonstrate meaningful learning, to produce creatively, to possess adequate 
knowledge regarding ethics, digital rights and responsibilities pertinent to both themselves and others, to be able to use appropriate computer platforms and digital tools, to use technological methods to generate problems, to work effectively as part of a local or global team, and to use digital tools in order to enhance learning through collaboration with others (ISTE, 2008, 2016).

For this reason, learning environments in which different technological tools are used and relevant environments designed and applied are needed in order to train students with the appropriate skills. Moreover, in addition to keeping pace with emerging technologies, high-level thinking skills that today's students are expected to possess, as well as being guided by students as digital citizens, have become extremely important. In this regard, as high-level thinking skill, 3D thinking, mental stimulation and rotation emerge as skills that students can gain (Brudigam \& Crawford, 2012; Sorby, 1999; Turğut, 2007), many researchers have suggested that spatial ability can be gained with the help of the appropriate environments, events, and technology access (Brudigam \& Crawford, 2012; Contero, Company, Naya, \& Saorín, 2006; Turğut, 2007). In such a designed environment, students can be trained as productive, aesthetically-aware, sensible individuals who can utilise information technologies effectively, look at problems from different angles, and generate their own ideas about geometrical objects at the same time (Kurtuluş, 2013; Rafi, Anuar, Samad, Hayati, \& Mahadzir, 2005; Turğut, 2010).

Without even realising, humans utilise spatial ability skills in everyday life. Yurt and Sünbül (2012) mentioned that we use spatial ability while trying to find our way through a city on our first visit there by way of map-reading, or in parking a vehicle, stacking dishes into a dishwasher, arranging objects or furniture in a room, playing tenpin bowling, or even just walking down the road. Moreover, professions such as architecture, astronomy, biochemistry, biology, chemistry, cartography, engineering, geology, mathematics, music, and physics all depend on spatial rather than verbal abilities (Bannatyne, 2003). In these branches of science, success is limited with inadequate spatial abilities (Hartman \& Bertoline, 2005). Rafi et al. (2005) indicated that spatial ability is an important human skill used as a measurement of effectiveness in learning, education, work, and even when playing games. At the same time, they argued that problem solving is one of the cognitive methods especially used in the management and processing of visuospatial information. Many scholars noted that spatial ability is used as a form of measurement in mathematics, technical drawing, graphics, science education, physical education, and in training therapy, and emphasised the importance of spatial ability in intensive visuospatial specialisations such as engineering, architecture, aircraft piloting, and in technical training.

Crano and Johnson (1991) and Pribyl and Bodner (1987) mentioned that although spatial ability is often overlooked as a curriculum target, it is important in the learning of many concepts and skills. This is also why researchers investigate spatial ability by examining its different components (Kurtuluş, 2013). Without spatial ability, it would be difficult to exist in today's world, because of our inability to understand the positions and relationships between objects and to understand changes, direction, and reception that may occur in the dimension or position of certain shapes (Smith, 1998). 
Spatial ability, which has a significant effect on daily life and our professional success, has become extremely important. In particular, the earlier that students become acquainted with this skill, the easier it is to develop and support this skill. According to Piaget, the period in which spatial thinking begins and develops the most is the second stage of primary education (Kakmac1, 2009), and research has revealed that the spatial ability of students at the second stage of primary education is at a very low level (Turğut, 2007). Moreover, studies on spatial ability comprise typically of geometry and mathematics at the secondary school level, with academic research focused on the Sketchpad, Cabri, and Virtual 3D programs designed especially for geometry teaching in recent years (Baki, Kösa, \& Güven, 2011; Cohen \& Hegarty, 2008; Güven \& Kösa, 2008). When the research was examined, no existing studies were found with the variables discussed in the context of research with sixth-grade students using Tinkercad. Furthermore, it is clear that the effects of the activities discussed in the current research will meet the needs for pedagogical support in teaching and assessing spatial ability as a thinking skill. Therefore, further studies are needed in order to confirm the effectiveness of the activities and the teaching process. Additionally, teaching this skill within an information technologies and software course is also thought to provide significant benefit both in terms of interdisciplinary study and in support of students' more efficient application of technology. Therefore, it is thought that studies on the development of individuals who effectively use 3D technology to support 3D thinking skills, especially those studies with students transitioning from the concrete to the abstract, will contribute to the literature. Therefore, the aim of the current study is to explore the contributions of creating 3D designs using a 3D design program to sixth-graders' spatial visualisation and mental rotation skills. In order to accomplish this general aim, the following research questions have guided the current study:

1. Do web-based 3D design applications enhance students' spatial visualisation skills?

2. Do web-based 3D design applications enhance students' mental rotation skills?

3. Do web-based 3D design applications enhance the ability of students to visualise the cross-sections of objects?

a. Do the 'Spatial Visualisation' final test scores of students show a significant difference?

b. Do the 'Spatial Rotation' final test scores of students show a significant difference?

c. Do the 'Santa Barbara Solids' final test scores of students show a significant difference?

\subsection{What is Spatial Ability?}

There have been markedly different definitions put forward for spatial ability and spatial ability skills, and whether or not it is to be considered a talent or skill is also a matter of debate. Educational psychologists have explained that ability comes from birth but skills are acquired through education (Sorby, 1999). Different researchers have also 
used concepts such as 'spatial skill', 'spatial perception', 'spatial reasoning', 'spatial visualisation', 'visual-spatial ability', and 'spatial perception ability' in reference to the term 'spatial ability' (Clements \& Battista, 1992; Linn \& Petersen, 1985; Olkun, 2003; Turğut, 2007). D'Oliveira (2004) stated that researchers have been unable to reach consensus in the four main themes when describing spatial ability; which are; a) different definitions for spatial skill and ability, b) the number of spatial ability types, c) different numbers and names given to define the subcomponents of spatial ability, and d) the existence of very different tests that measure the different subcomponents of spatial ability.

Ekstrom, French, Harman, and Dermen (1976) defined spatial ability as the ability to perceive spatial form, or the ability to orient in new situations. Carroll (1993), Gardner (2011), and McGee (1979) all pointed out that the ability to mentally manipulate, rotate, bend or invert a pictorial stimulus object is one aspect of multiple intelligence. According to Lohman (1993), spatial ability is the ability to bring a visual image to a form, to follow-through an image, to rearrange it, and to transform it in another way. On the other hand, Linn and Petersen (1985) described spatial ability as symbolic and nonverbal information used as skills in describing, transforming, shaping, and remembering. Stockdale and Possin (1998) noted spatial ability as the ability to establish spatial relationships between a person and their environment. They stated that spatial relations comprise of properties such as size, distance, volume, order and time; for example, the layout of objects on a table, the distance between the objects, the alignment of letters in a word, the time marker separations of a clock face, the deviating activities, or the steps of a simple division process (Yurt \& Sünbül, 2012).

Olkun (2003) defined spatial ability as the ability to recall, rotate, and interpret twoand three-dimensional objects in the mind, while Turğut (2007) defined spatial ability as the ability to move or reconstruct objects and components in the mind three-dimensionally that are composed of one or more parts. Rafi and Samsudin (2009) recognised spatial ability as an important human skill involving the acquisition, retention and transformation of visual information in a specific context, whilst Gardner (2011) suggested that this ability emerges when a person finds out what an object looks like when it is mentally rotated at a certain angle to copy or perceive a shape. The National Research Council (2006) defined spatial thinking or reasoning as the involvement of the location and movement of objects, either mentally or physically, that refers to a considerable number of concepts, tools and processes. According to Wai and Uttal (2018), spatial skill is 'the ability to generate, retain, retrieve and transform well-structured visual images that is related to the shape, size, orientation location direction or trajectory of objects and their relative positions' (pp. 1-2).

When these various studies are reviewed, there are many similarities to be seen in the definitions that they have each put forward, but that they concentrate on certain points. Most used wording in their definitions based on concepts such as space, objects in space, mental manipulation of objects, movement of objects, transformation, and their relations with each other. Therefore, spatial ability can be defined as, "the ability to realise the mental transformation of objects in space, to visualise how objects look at different angles, and to understand how objects are related to each other'. 


\subsection{Subcomponents of Spatial Ability}

In the literature, along with so many different definitions for this concept, are also numerous terms used to define the subcomponents of spatial ability. McGee (1979) divided spatial ability between 'spatial visualisation', where there is an activity in which all parts of the object are moved, and 'spatial orientation', in which not all parts of the object are moved. Linn and Petersen (1985) studied spatial ability as three different categories: 'spatial visualisation', as the ability to compose various spatial details when necessary to produce the correct solution; 'spatial perception', as the ability to identify spatial relationships despite mixed information; and 'mental rotation,' the ability to rotate 2D and 3D objects in the mind, quickly and accurately. Some researchers (e.g., Burnet \& Lane, 1980; Clements \& Battista, 1992; Olkun \& Altun, 2003; Pellegrino, Alderton, \& Shute, 1984; Turğut, 2007) simplified this classification with only two categories: 'spatial visualisation', as the visualisation of 2D and 3D objects with more than one part and the ability to visualise new situations that will occur by moving images of their parts in $3 \mathrm{D}$; and 'spatial relations', as the ability to rotate 2D and 3D geometric forms in the mind as a whole, and to be able recognise them at various locations.

Tartre (1990, as cited in Sorby, 1999) distinguished two components of spatial ability, as 'spatial visualisation' and 'spatial orientation'. The 'spatial visualisation' component includes the mental movement of an object and has two subcomponents of 'mental rotation' and 'mental transformation'. The difference between these two subcomponents is that; in 'mental rotation', the object is rotated in the mind as a whole; whereas in 'mental transformation', some part of the object is transformed into another form. The 'spatial orientation' component includes the ability to imagine a different aspect of that object while the object is stationary in space. Maier (1998) suggested five components that constitute spatial ability as; 'spatial visualisation', 'spatial perception', 'mental rotation', 'spatial relations', and 'spatial orientation'. Table 1 presents the subcomponents of spatial ability according to a compilation of the research of Turğut (2010), Yıldız and Tüzün (2011), and other related studies.

\subsection{D Design Programs and Spatial Ability}

Brudigam and Crawford (2012) stated that spatial ability could be improved through the performing of many different activities, such as playing 3D computer games, using geometric shapes in mathematics lessons, and drawing engineering course graphics either manually or with the aid of a computer program. In 3D modelling training, a virtual 3D model is created or the process involves representing geometric objects in space on a computer screen. In this way, an object can be presented in a 3D perspective that can help anyone who tries to understand the 3D space. Special programs for 3D modelling software generate the visible image of an object. Free computer-aided design (CAD) modelling software programs are available on the Internet. Some of the popular programs are OpenCAD, FreeCAD, SketchUp, 123D Design, Meshmixer, Tinkercad, 3DTin, Blender, Sculptris, WeDesign. Live, and Smoothie-3D. There are also websites 
Table 1

Researchers Describing Subcomponents of Spatial Ability

\begin{tabular}{llllll}
\hline & $\begin{array}{l}\text { Spatial } \\
\text { Visualisation }\end{array}$ & $\begin{array}{l}\text { Spatial } \\
\text { Orientation }\end{array}$ & $\begin{array}{l}\text { Spatial } \\
\text { Relations }\end{array}$ & $\begin{array}{l}\text { Mental } \\
\text { Rotation }\end{array}$ & $\begin{array}{l}\text { Spatial } \\
\text { Perception }\end{array}$ \\
\hline McGee (1979) & + & + & & & \\
Burnet \& Lane (1980) & + & & + & & \\
Pellegrino et al. (1984) & + & & + & & + \\
Linn \& Petersen (1985) & + & & & + & + \\
Tartre (1990*) & + & + & & & + \\
Clements \& Battista (1992) & + & + & & \\
Maier (1998) & + & + & + & + & \\
Sorby (1999) & + & + & & & \\
Olkun \& Altun (2003) & + & & + & & \\
Kayhan (2005) & + & + & & & \\
Turğut (2007) & + & & + & & \\
\hline
\end{tabular}

*as cited in Sorby (1999)

hosting open-source 3D CAD model libraries. Such ready 3D modelling programs are able to be downloaded to a personal computer and some of the existing CAD programs allow modification of the models.

As seen from a review of the literature, 3D design programs such as Sketchpad, Cabri, Virtual 3D, and Google SketchUp have been used as a tool in many studies in order to develop spatial ability, especially in the fields of mathematics and geometry (e.g., Dorta, Saorín, \& Contero, 2008; Fleron, 2009; La Ferla et al., 2009). CAD-type programs, where the effects on spatial capability are examined, are used in engineering and technical drawing lessons, and it is stated in many studies that such programs can positively influence spatial skill development. Norman (1994) noted the importance of spatial visualisation in computer-based technology over 20 years ago, and stated that spatial visualisation was a critical skill for using and interacting with computer-aided technology (CAx) tools. Christou et al. (2007, as cited in Yüksel \& Bülbül, 2014) argued for the necessity of dynamic and interactive computer applications that feature the appropriate $3 \mathrm{D}$ objects to enhance $2 \mathrm{D}$ and $3 \mathrm{D}$ spatial visualisation and reasoning capabilities. At the same time, Kurtuluş (2013) cited both Calcaterra, Antonietti, and Underwood (2005) stated that computer-assisted instruction had recently been used to develop spatial ability.

In the current study, the Tinkercad 3D design program ${ }^{1}$ was used because of its zero cost for users, being readily available on the internet, and for its ease of use by both primary and secondary school students. Tinkercad was launched in 2011 and, according to the Tinkercad's home page, some four million designs have been made by its users, with hundreds still being added daily. The program can be used by teachers,

${ }^{1}$ https://www.tinkercad.com/ 
students, hobbyists, and designers in order to imagine, design, and create virtually anything. Tinkercad is considered to be an easy and enjoyable tool to learn among the available CAD programs. According to the literature review, no existing studies were found that measured the effect of Tinkercad usage on users' spatial ability. Therefore, it is considered that the current study will provide a roadmap of activities for teachers looking to support and develop the spatial abilities of their students using such a tool.

\subsection{Research on 3D Design Programs and Spatial Ability}

In a study by Sorby and Baartmans (2000), a course was opened for first-grade engineering undergraduate students with low 3D spatial visualisation skills in which I-DEAS computer software was employed with the aim to develop these skills. At the end of the study, it was determined that the students' scores had increased significantly. Rafi et al. (2005) used a Web-based Virtual Environment (WbVE) with the aim to improve the perception of junior high school students' spatial ability in engineering drawing instruction. As a result of their study, it was concluded that the virtual environment was much more effective than the classical classroom environment in the development of the students' spatial capability. Basham and Kotrlik (2008) conducted a study with ninthgrade students of a Flight Technology Discovery course in Mississippi, and determined that there was a statistically significant difference in terms of the methods used with $3 \mathrm{D}$ CAD modelling software.

Cohen and Hegarty (2008) investigated the effects of interactive computer animation and visual geometric objects used in virtual 3D software on the spatial visualisation activities of university students with low spatial ability. As a result of the application, it was observed that the ability of the participant students to visualise the cross-sections of object surfaces increased significantly. Toptaş, Çelik, and Karaca (2012) conducted a study to explore the effect of the 3D Modelling program on the spatial ability of eighth-grade students. According to the findings of their study, post-test success rate increased after the application in terms of differential ability, mental rotation, and spatial visualisation. David (2012) worked with various computer games (Shapes, Block-out, 3D Blocks, Cram jam, Cyclanoid, and Kiki the nano bot) that require visuospatial ability. The scores before and after training with ANOVA test were compared and showed significant differences, with students with low spatial ability identified as the group that had benefited the most.

Chang (2014) investigated the 3D CAD applications' helpful effects on creative design performance for users with different spatial abilities. Among the results of the study was a moderately positive correlation found between students' spatial ability and their creative performances, and functional creativity showed the strongest correlation in this context. Özcan, Akbay, and Karakuş (2015) examined the effects of widespread technology use and visual enhancement in computer environments on spatial ability. As a result of their study, the researchers pointed to a positive correlation having been between spatial ability and computer and gaming experience. 
Lin and Chen (2016) focused on the development of spatial visualisation and mental rotation, two important components of spatial ability, through puzzle gaming. The findings of their research showed that the puzzle games effectively improved the participant players' spatial visualisation and mental rotation capabilities, and that traditional puzzle games enhanced the mental rotation of the participants. Cho (2017) questioned how creativity, spatial ability, and visual cognitive styles of students related to their performance in a design studio course measured in the classroom. In their analysis, there was no correlation seen between the studio course grade and the scores observed; however, there was a positive correlation found between the participants' general spatial ability and visual cognitive styles. It was also determined that the male participants performed better than their females peers in general spatial ability tasks and in the tendency of spatial visualisers.

When the literature about computer-aided design and spatial ability was reviewed; a significant increase in the spatial ability of study participants was found in almost all of the published research, despite the wide range of the research that included engineering students, candidate teachers, junior high school and high school students, and a number of different 3D design tools used in the studies, as well as different spatial ability tests applied, and different subcomponents of spatial ability being measured. In the research; in addition to $3 \mathrm{D}$ design tools, when variables such as experience in using computer games, playing computer games, and solving puzzles on computers were also considered, an increase in these abilities was observed. Furthermore, since the design process triggers creativity at the same time, the research has shown that students with higher spatial ability are more creative and more aesthetically-minded. However, no studies were found to have been conducted with sixth-graders using the 3D design tools within an information technologies and software course that focused on the subcomponents of spatial thinking skills.

\section{Method}

\subsection{Research Design}

In the current study, a single group pre-test and post-test design was used to collect the quantitative data. The independent variable of the research was web-based threedimensional design applications. The dependent variables of the study were four distinct sub-dimensions of spatial capability: 'visualisation of objects in different directions' (for spatial visualisation), 'objects in the mind' (for mental rotation), and 'visualisation of cross-section of objects' (for both spatial orientation and spatial relations). Then, focus group interviews were held to collect data for the qualitative dimension of the study in order to explain and elaborate upon the quantitative results. 


\subsection{Study Group}

The study group of the current research consisted of a total of 63 students studying in the sixth grade of a private secondary school. The researchers conducted the study within an Information Technologies and Software course with students of the school. The participating students were all 12 years of age, with 30 (47.6\%) females and $33(52.4 \%)$ males. All of the students had received Information Technologies and Software courses since their third grade, but none had previously used the Tinkercad software.

\subsection{Data Collection Tools}

In this study, data were collected using the Spatial Visualisation Test (SVT), Mental Rotation Test (MRT), and Santa Barbara Solids Test (SBST). The three tests were carefully selected among the many spatial tests available after taking into consideration the appropriateness of each test to the age group of the participants.

\section{Spatial Visualisation Test (SVT)}

The participant secondary school students took the SVT using the 'Middle Grades Mathematics Project: Spatial Visualisation' book, published by Winter, Lappan, Philips, and Shroyer (1989), and adapted into Turkish by Yıldız (2009). Yıldız (2009) started his study with three schools and applied SVT test as a pre-test. The reliability coefficient of the test was calculated as $.679(n=161)$ for the post-test. Ylldiz then continued the study with two schools, and recalculated the reliability coefficient to be $.971(n=108)$. The test generally consists of questions based on predicting the appearance of shapes formed from above, side-by-side, from the front, from the back, from the right, or from the left. The test consists of 15 questions, each with five options.

\section{Mental Rotation Test (MRT)}

The MRT was first developed by Vandenberg and Kuse (1978) and was then revised by Peters et al. (1995). It was then later adapted to Turkish by Yildız (2009). Yildiz (2009) started his study with three schools and applied the MRT as a pre-test. He then continued the study with two schools and recalculated the reliability as .661 $(n=108)$. The test consists of 24 questions that measure the ability to imagine shapes formed by turning them in various directions. All of the questions are of the same format, with two of the four possible answers being correct. In the test, 1 point is awarded for each correct answer, with 48 points being the maximum score obtainable.

\section{Santa Barbara Solids Test (SBST)}

Developed by Cohen and Hegarty (2007), the SBST was adapted into Turkish by Uygan (2011). There are a total of 30 questions aimed at measuring the ability to visualise the interfacial surfaces of objects. Each question has four possible answers. 3D images 
of single, interlocked, or interlocking multiple, horizontal, vertical, and oblique planes are shown, with questions answered as if looking directly from the horizontal, vertical and oblique section.

\section{Focus Group Interview}

Focus group interviews were held in order to elicit students' detailed thoughts about the study, and also to reveal more about their achievements during the study. The interview questions were prepared in advance. In order to ensure content validity of the interview questions, the prepared questions were reviewed by experts from the fields of educational technology, measurement and evaluation, and language teaching. Based on the expert reviewers' comments, some of the questions were revised and some thought to be overly complex were reworded.

The focus group interview was conducted with a total of 21 students having different spatial ability levels. During the interview, the participants' were both audio and video-recorded, with their permission, and then the recorded data transcribed and evaluated according to qualitative data analysis methods as a means to support the quantitative research.

\subsection{Process of the Study}

Prior to the commencement of the study, correspondence was made with the school administration, and permission granted for the application of the study. In addition, the participant students' parents were also duly informed. In the 3D design models to be constructed using the Tinkercad program, first, the lessons were conducted based on the simple-to-hard and induction methods. The use of the Tinkercad program was taught to the students as part of their weekly work. The process and schedule of the application is shown in Table 2.

An interdisciplinary study was conducted by the mathematics teacher of each class for a period of 2 hours in order for the students to learn and develop spatial knowledge, and to increase their motivation towards spatial thinking and expansions, which is another subcomponent of spatial ability (see Fig. 1). It is notable to mention here that no similarity existed between the questions asked in the focus group interview and the test questions applied in the study.

Students were asked to visualise the folded shapes of unfolded figures that were projected onto the screen, and then to see create the objects manually by folding the unfolded shapes distributed to them in order that they could visualise the figures in a concrete way. In the first six questions directed to the students, 3D objects were provided along with the visual solution (see Fig. 2), and then the students folded the paper in a concrete way to replicate the object.

In the following six questions, each question was first displayed on the screen and then the students were asked to come up with solutions in their mind. Later, the students were asked whether or not they enjoyed folding the shapes whilst solving the questions, 


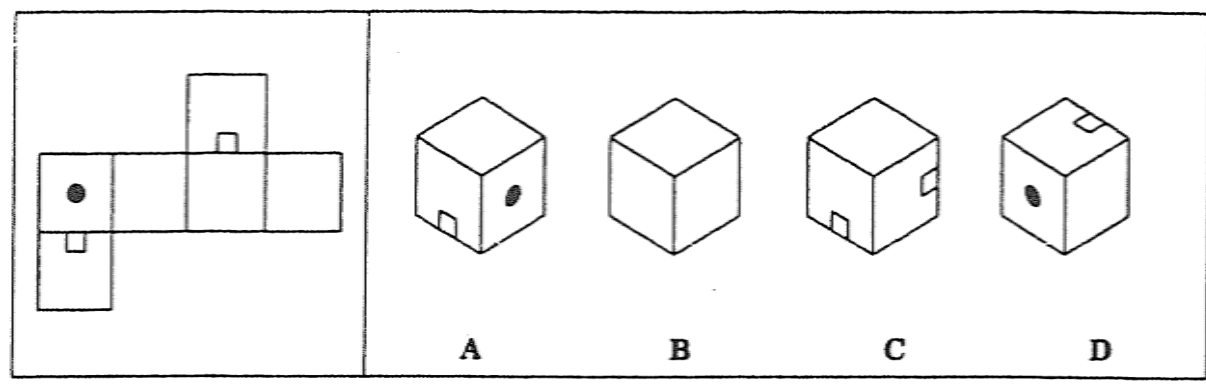

Fig. 1. An Example Question with Mathematics Teacher.

Table 2

Process of the Study

\begin{tabular}{lll}
\hline Week & Content & Remarks \\
\hline Week 1 & $\begin{array}{l}\text { Preparatory } \\
\text { work }\end{array}$ & $\begin{array}{l}\text { Launched as an interdisciplinary study with the mathematics teacher of the } \\
\text { participant school. Study aim was to increase motivation for spatial thinking and to } \\
\text { remind learners about expansions; a different spatial ability sub-dimension. }\end{array}$
\end{tabular}

Week 2 Pre-test Spatial visualisation, mental rotation, and cross-sectional testing was applied as a application

Week 3 3D design, Demonstration of how to use 3D design models and design programs to design 3D printer, products to be made on a 3D printer. Introduction to Tinkercad application Tinkercad and interface, ensuring each student was added as a member in order to use the application online.

Week 4 3D home Demonstration of how to create a simple home design using Tinkercad's geometric design shapes. Using ruler tool and Holl key together with emptying of figures, grouping method, and adjust/align command to align shapes in desired directions. During second lesson, students designed their own home.

Week 53 D car design Demonstration of how to create a simple car design using Tinkercad's geometric shapes. Duplicating wheels with Ctrl+D and other methods, plus snap-grid tool. During second lesson, students created their own car design.

Week 6 3D dog and Demonstration of how to create a dog and dog club design using Tinkercad's dog club geometric shapes. Incorporating existing shapes into designs using the Community design section. During second lesson, pupils created their own dog and dog club designs.

Week 7 3D game park Demonstration of how to design a playground swing using Tinkercad's geometric design shapes. During second lesson, students created their own playground.

Week 8 3D city plann- Students created their own city plans by combining work from the previous week. and 9 ing design Demonstrated the development of workspace with edit grid. Students were tasked with adding some genuine design elements to their city plans.

Week 10 Application of Application of spatial visualisation, mental rotation and cross-sectional testing as a final tests final test to determine if the training had the potential to influence spatial ability.

Week 11 Focus group Focus group meeting held with seven students from each branch (21 in total). interview 

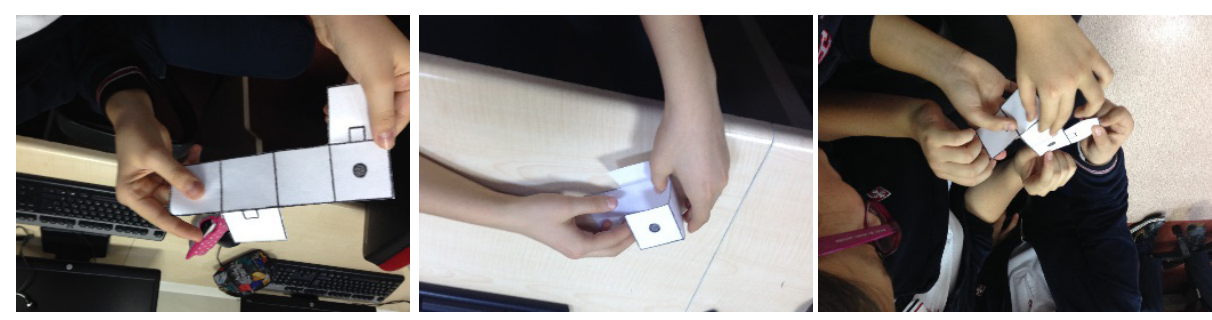

Fig. 2. Folding of Figures.
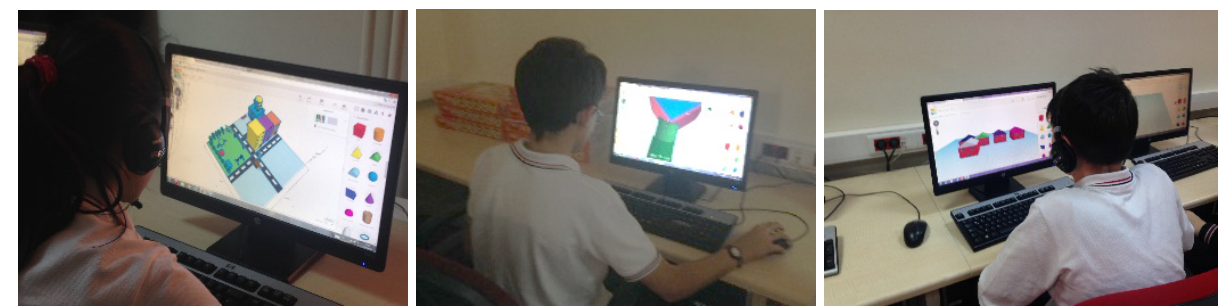

Fig. 3. City Plan Design with Tinkercad.

or whether they had preferred finding the answers just in their minds. The students generally stated that they enjoyed the practical solution method more than trying to resolve the question just in their minds. The students were provided with information on $3 \mathrm{D}$ design models, design programs, and how the designed products could be created as output from a 3D printer. Then, the Tinkercad application and its interface was introduced, with each student created as individual users in order for them to use the application online, and to complete the weekly activities (see Fig. 3).

\subsection{Analysis of Data}

The analysis of the data was performed using IBM's SPSS Statistics program. The pre-test and post-test scores of the SVT, MRT, and the SBST were analysed using $t$ test, with a .05 level of significance. In the qualitative part of the study, a focus group interview was conducted with a total of 21 students. The interview was both audio and video recorded. Afterwards, the transcript of the answers given to the questions was descriptively analysed, and a themes and frequency table related to the opinions was created. The findings were then directly related to the findings of the related interview questions. For the reliability of the codes generated in the data analysis process, half of the data was reanalysed by the same researcher after a lapse of 4 months. The reliability value between the two coding results was then calculated and the result was found to be .87. As a result, consistency between the results of both coding processes was found to provide the required level as proof of its reliability. 


\section{Results}

\subsection{Pre-Test and Post-Test Scores}

In order to check whether or not there was a meaningful difference between the pre-test and post-test scores of the three different tests applied in the study, $t$-test was performed for each group separately. The scores of each test are presented in Table 3 as an overview of the results.

\section{Spatial Visualisation Test Results}

It was researched whether or not the applications in Tinkercad had an effect on the students' spatial visualisation, a sub-dimension of spatial ability. The $t$-test was applied in order to see if there was a significant difference between the pre-test and post-test scores of the students' SVT. The results of this test are presented in Table 4.

As can be seen in Table 4, a difference of .05 significance level was found between the pre-test and post-test scores in terms of the students' SVT scores. It can therefore be seen that the lesson taught using the Tinkercad application contributed positively to the performance of the students' SVT, and hence to the spatial visualisation ability of users with lower levels of spatial ability. This result supports Research Question 1, which is 'Do web-based 3D design applications enhance students' spatial visualisation skills?'

Table 3

Pre-test and Post-test Test Scores

\begin{tabular}{lllllr}
\hline Test & & $N$ & $M$ & $S D$ & $S E M$ \\
\hline Spatial Visualisation Test & Pre-test & 63 & 5.36 & 2.90 & .36 \\
& Post-test & 63 & 6.98 & 3.37 & .42 \\
\multirow{2}{*}{ Mental Rotation Test } & Pre-test & 63 & 34.01 & 8.49 & 1.06 \\
& Post-test & 63 & 37.80 & 7.90 & .99 \\
\multirow{3}{*}{ Santa Barbara Solids Test } & Pre-test & 63 & 12.69 & 5.30 & .66 \\
& Post-test & 63 & 14.17 & 5.98 & .75 \\
\hline
\end{tabular}

Table 4

Pre-test and Post-test Results of Spatial Visualisation Test

\begin{tabular}{lllllll}
\hline & $M$ & $S D$ & $M S E$ & $t$ & $S D$ & $p$ \\
\hline SVT Pre/Post-Test Results & -1.619 & 2.465 & .310 & -5.212 & 62 & .000 \\
\hline
\end{tabular}


Table 5

Pre-test and Post-test Results of Mental Rotation Test

\begin{tabular}{lllllll}
\hline & $M$ & $S D$ & $M S E$ & $t$ & $S D$ & $p$ \\
\hline MRT Pre/Post-test Results & -3.793 & 6.691 & .843 & -4.500 & 62 & .000 \\
\hline
\end{tabular}

\section{Mental Rotation Test Results}

It was researched whether or not the applications in Tinkercad have an effect on the students' mental rotation ability, a sub-dimension of spatial ability. The t-test was applied in order to see whether or not there was a significant difference between the pre-test and post-test scores of the students' MRT. The results of the test are presented in Table 5.

As can be seen in Table 5, there was a significant difference found between the pre-test and post-test scores in terms of the students' MRT performances. It is seen that the lesson taught using the Tinkercad application contributed positively to the students' mental rotation ability as users with lower levels of spatial ability. This result supports Research Question 2, which is 'Do web-based 3D design applications enhance students' mental rotation skills?'

\section{Santa Barbara Solids Test Results}

It was researched whether or not the applications in Tinkercad had an effect on the students' intersection or cross-section acquisition ability, which is a sub-dimension of spatial ability. The $t$-test was applied in order to see if there was a significant difference between the pre-test and post-test scores of the students' SBST. The results of the test are presented in Table 6.

As can be seen in Table 6, there was a significant difference found between the pretest and post-test scores of the students' SBST performances. It is seen that the lesson taught using the Tinkercad application contributed positively to the SBST results and therefore to the students' ability to visualise the cross-section of an object, which is a subcomponent of spatial ability. This result supports Research Question 3, which is 'Do web-based 3D design applications enhance the ability of student to visualise the crosssections of objects?'

Table 6

Pre-test and Post-test Results of Santa Barbara Solids Test

\begin{tabular}{lllllll}
\hline & $M$ & $S D$ & $M S E$ & $t$ & $S D$ & $p$ \\
\hline SBST Pre/Post Test Results & -1.476 & 4.672 & .588 & -2.508 & 62 & .015 \\
\hline
\end{tabular}




\subsection{Qualitative Research Findings}

In order to support the quantitative research results, mixed methodology was employed and open-ended questions about the topic of study were directed to the students following completion of the application. The focus group interviews were conducted with 21 students who were the most, moderate and least successful according to the scores they received in the test. The students were interviewed for a total period of 2 hours.

\section{Students' Opinions on 3D Design or 3D Modelling}

'What does 3D design or 3D modelling mean for students?' and 'What comes to your mind about 3D?' were the questions asked. In this context, three of the students described 3D design as looking at a shape from all sides, while two students described it as touchable things, two students described it as seeing things in a more detailed view, one student described it as 'objects having volume', one student described it as objects having thickness, length and objects with a certain width, whilst one student stated that Tinkercad came to mind in terms of 3D design. Some of the students' opinions from the answers given are as follows;

An object is supposed to be voluminous as in our lives. For example, when we draw a picture, we see it only in $2 D$ and there is no certain volume or weight, but $3 D$ objects do seem to have a certain weight and volume. (Student 1)

We have learnt since the second grade that $3 D$ objects are the product of the width, length and height as volume calculation. The calculation of their volume comes to my mind in the sense of $3 D$ objects. Nothing has changed since I first saw Tinkercad. It is still the same thing as $3 D$ objects. (Student 2)

\section{Students' Opinions on the Positive Aspects of 3D Model Development}

The students were asked, 'What are the positive aspects of developing 3D models?' While three students said it contributed to their learning, two students expressed that it could help with career selection in the future; two students indicated that it would be useful for designing animations, four students related the positive aspects of 3D modelling development to contributing to animation. In this regard, one student stated;

It develops our mind. For example, when we put a preliminary chair, it can contribute to seeing it all around. Therefore, when we look at it from the front, it can help us to imagine the back of it. Without seeing the back of an object or a corner of it, it may help us to visualise it in our mind as if we had seen it before. (Student 8) 


\section{Students 'Definition and Opinions on Spatial Ability}

Students were asked 'How do you describe spatial ability?' and 'Which talents fall within the scope of spatial talent?' When the students were asked about the definition of spatial ability, three of the students defined 3D objects as imaginary rotation, three students defined spatial visualisation, three defined the ability to visualise in the mind, two students stated having the ability to look at the side view when cut from one place, one student described it as tests applied in the class, and one student described it as a mat plan of an object. Some of the students' opinions on this subject were as follows:

It is a form of spatial ability to be able to stack dishes in the dishwasher. Because we turn the dishes visually in our minds to find out how we can put more dishes in by arranging them in our mind before putting them into the machine. (Student 4)

Speaking of spatial ability, we have certain tests that we do. In our minds comes the ability to rotate three-dimensional objects. For example, we can rotate a body of $L$ shaped cubes in our own mind - this is spatial ability. At the same time, when you see an object, even if you are unaware of it, if you have spatial ability, you can visualise it in your mind as well. (Student 5)

\section{Students' Opinions on the Use of Tinkercad}

The students were asked what they thought about using Tinkercad, a web-based 3D design program, and whether or not they enjoyed using it. When considering the positive opinions of the students, five of the students mentioned its contribution to creativity, three students said that it strengthened their imagination, three students found it very entertaining, two students said that it was easy to use, two students liked it very much, two students said it was very useful, and one student found it very helpful in contributing to shaping the angle of view. Some of the students' opinions on this subject can be exemplified as follows:

I saw some $3 D$ designs in some programs created before learning about Tinkercad, but I was wondering how they were created. Then you told us we were going to do $3 D$ work on a website called Tinker$\mathrm{cad}$. From the moment we studied Tinkercad, I gradually learnt how to create games like Minecraft. For example, we can download maps from Tinkercad to games such as Minecraft to play. We have a section at the bottom and we can load the map from there. Therefore, Tinkercad contributed to us in many areas. (Student 2)

Tinkercad is actually a well thought-out program. Not just because it is useful, but also that you can produce many things using very few objects. (Student 12) 
When the negative student opinions regarding the use of Tinkercad are considered; three students stated that they had difficulty in using the program until getting accustomed to it, three students experienced problems recording due to the program being online, three students had problems with its camera control, two students had difficulty in aligning objects, two students experienced problems in two colour combinations, two students mentioned the downside being that it only had an online version, and two students stated that the program had no Turkish language support. Some of the students' opinions on this subject can be exemplified as follows:

When we combine and group two objects in different colours and then we want to duplicate it and change the colour, I wish that the program would let me paint two objects in different colours without having to ungroup them. (Student 7)

There is a problem with saving. Because it saves every move when recording, it means that even the directional keys on the keyboard, including the forward and backward movement and the left and right is recorded, so the operating system on the computer is very slow which can be a pain as the process can take a long time. It would be better if Tinkercad could also be used offline, like Scratch for example, rather than only being available online. (Student 12)

\section{Opinions about Which Skills are Contributed to by the Tinkercad Application}

Students were asked, 'What do you think Tinkercad's contribution to your ability is most?' In this respect, five students indicated that Tinkercad contributed mostly to their imagination, three students said 3D thinking, and two students said that it contributed to being able to look at an object from all angles. In this regard, one of the students stated;
I also think that it makes a great contribution to your imagination. You are imagining something, then you can create what you imagined, and then you want to imagine more. (Student 10)

Student Comments on How 3D Model Development Using Tinkercad Contributed to Spatial Visualisation, Mental Rotation, and the Ability to Imagine the Cross-Section Surfaces of Objects

Student opinions were asked about three separate test subjects applied to the students. The opinions of each subject were presented in separate tables. Using Tinkercad, three students increased their spatial visualisation ability, five students increased their ability to look at an object from different angles, two students increased their ability to visualise in their mind, while two students gained the ability to translate new shapes. In this regard, one of the students stated; 
When you look at an object from the front, you can get an idea of how it looks from the right or from the left. I think it contributes to the ability to look at an object in particular from different angles. (Student 5)

When the students were asked about Tinkercad's contribution to their mental rotation ability as a 3D model developer, five students indicated that they could resolve questions about mental rotation more easily, three students could resolve questions about mental rotation much more quickly, and three students benefited from the mental activities. In this regard, one student mentioned;

At the beginning, I was spending a lot more time trying to solve these tests in order to find the rotated state. However, after using Tinkercad I started to sort out these kinds of questions much faster. Before I saw Tinkercad I was unable to solve these kinds of questions, but after using Tinkercad I can't say that I solve such questions completely, but I have now started to solve these questions by spending less effort in a shorter amount of time. (Student 15)

When the students were asked about Tinkercad's contribution to their ability with 3D modelling to view cross-sections of an object, four students indicated that they were now able to view slices of objects in their mind, and two students indicated that they were able to visualise the movement of objects in their mind. One student in this regard said that;

I think that if we chose to be a surgeon, for example, in the future, it [Tinkercad] would contribute to our ability. Because, as surgeons, we may need to cut out an organ or reattach something. When we need to cut a piece, we may need to guess what the remaining pieces would look like. Tinkercad can help us to do this with the "Holl" key. Therefore, seeing it improves our ability to cross-section. (Student 9)

\section{Students 'Opinions on the Contribution of Tinkercad to Their Future Profession}

The students were asked, 'What do you think the use of Tinkercad contributes to the profession that you plan to choose in the future?' Five students answered that the use of Tinkercad could contribute to the architecture profession they thought they might choose in the future. Four students said that it could contribute to being a civil engineer, two students said being a mechanical engineer, two students said a medical doctor, one student said a teacher, one student said a painter, and one student mentioned the profession of a sculptor. Some of the students' opinions on this subject can be exemplified as follows:

It is not a profession that I think for myself just yet, but I think that it could contribute to being a professional architect. In that way you can show the person who wants to see the building before drawing the plans, and they can see and change the places they do not like beforehand. (Student 19) 
[Tinkercad] Contributes to those who may deal with art or as a painter. Some painters work with $3 D$ hapes. For example, 3D studies can be done within a technology design course. They also contribute to this work. (Student 8)

\section{General Student Opinions on the Implementation Process with Tinkercad}

The students were asked, 'What would you suggest should be changed in this study on the use of Tinkercad, if this study were to be applied to another student group?' and 'How do you expect the application to be when assessed from the other students' and their teacher's point of view?' The students answered this question based on the topics they wanted to work on according to their own interests, rather than the directions to be changed or developed in practice. Considering the general student opinions on the application process with Tinkercad, five of the students mentioned that an object in real life can be transferred to a computer in $3 \mathrm{D}$, two students mentioned designing clothing, and two students mentioned the designing of replacement organs such as the stomach and heart.

\section{Discussion}

When the findings of the current study are examined, it can be determined that $3 \mathrm{D}$ design applications using the Tinkercad software significantly contributed to both the participants' spatial visualisation and mental rotation, and also to their ability to visualise the cross-section of objects. When the quantitative and qualitative findings are compared, it can be seen that the students' opinions about the implementation support the results of the quantitative study, and it also sheds light on the reasons behind the results.

The first question of the research was; 'Do web-based 3D design applications enhance students' spatial visualisation skills?' When the students' pre-test and post-test results were compared, it can be seen that there was a significant increase in their spatial visualisation skills. This may be due to the applications with Tinkercad providing opportunities for $3 \mathrm{D}$ virtual objects to be clearly seen from different angles. The answers to the focus group interview questions also pointed to the benefits of this study being able to see an object from all sides/angles, and thereby to develop their spatial thinking skills. This finding is consistent with the research of Olkun and Altun (2003), and the reported ability to visualise $2 \mathrm{D}$ and $3 \mathrm{D}$ objects through spatial visualisation in their work on moving parts of objects in space.

There was, however, no similar work found in the literature that measures the development of spatial ability using the Tinkercad tool, and so any comparison of the current study would only be applicable for studies that utilised other similar 3D design tools. Rafi et al. (2005) conducted a study in which prospective candidate teachers worked with secondary school students using a Web-based Virtual Environment (WbVE); the results of which showed improvements in the spatial ability understanding of engineering drawing instruction. According to their test results, spatial visualisation results were significantly higher in the final test results, which means that the virtual environment 
proved to be much more effective than the classical classroom environment. Although the research by Rafi et al. (2005) cannot be considered as a true comparison, the results of their study and the current study pointed to similar increases in the study participants' spatial visualisation, which indicates that the two studies' results support each other. Toptaş et al. (2012) conducted a study to explore the effect of the 3D Modelling program on the spatial ability of eighth-grade students. According to the findings of their study, the post-test success rate increased after the application in terms of the participants' spatial visualisation. On this point, the results of Toptaş et al. (2012) could also be said to support the results of the current study.

The second test of the current study was based on '3D design practices enhancing students' mental rotation skills'. When the pre-test and post-test results of the students were compared, a significant increase was seen in their mental rotation skills. It could be said that this increase is primarily due to Tinkercad users being able to translate $3 \mathrm{D}$ objects as they wished using the software and having learned to look at virtual objects in $3 \mathrm{D}$. When the answers to the focus group interview questions are considered, the students also stated that their increase in mental rotation performances was considered among the benefits of the study, and that they solved the questions in the final test much easier and faster following the activity application. In the studies they conducted, Kurtuluş (2013), Rafi et al. (2005), Sorby and Baartmans (2000), and Toptaş et al. (2012) all used different 3D design tools, but when examined, the results of each study reported significant increases in the respective participants' mental rotation performances. The conclusion that can be drawn from this is that applications made with $3 \mathrm{D}$ design tools can improve users' mental rotation skills, which is a sub-dimension of spatial ability.

Lin and Chen (2016) focused on the development of spatial visualisation and mental rotation, two important sub-dimensions of spatial ability, through puzzle games conducted in their study. The findings of their research showed that the designed puzzle games effectively improved the participants' spatial visualisation and mental rotation capabilities, and that traditional puzzle games can enhance the mental rotation of participants. McClurg, Lee, Shavalier, and Jacobsen (1997), Olkun (2003), Rafi, Samsudin, and Said (2008), and Subrahmanyam and Greenfield (1994) all conducted similar studies that investigated the effects of game-playing on spatial ability, and each found that it enhanced this ability.

The third and final test of the current study was based on '3D design applications with Tinkercad enhances students' ability to visualise the cross-section surfaces of objects'. When the pre-test and post-test results of the students were compared, a significant increase was seen in the students' ability to visualise the cross-section surfaces of objects. This increase was primarily due to students designing their own objects, and in their using Tinkercad to repeat the cross-section process frequently using the 'Holl' key, which contributed to their ability improvement. The students also pointed out in their focus group interview answers that the application contributed to them being able to slice objects in their minds, and that the movement of objects in their minds was enhanced through applications created in Tinkercad. Cohen and Hegarty (2007) reported 
that the cross-section surface resulting from a cut plane was visualised in the mind according to the structure of the object and the position/angle of the slice, while this surface was rotated in the mind or imagined from the point of view towards the surface. From this, it was proposed that spatial visualisation, spatial relations, and spatial orientation abilities are used together in the prediction of cross-section surfaces of objects (as cited in Uygan, 2011, p. 97).

It was also seen that when students' opinions about 3D design are examined, they defined $3 \mathrm{D}$ as being able to touch and feel shapes with a certain weight, width, and height, and being able to see them from the right, left, front, back, top, or bottom; in short, from all directions. It is thought that the students had a general idea about 3D prior to the start of the current study, but that they learnt much better because of their experiences 'creating' $3 \mathrm{D}$ designs that they are expected to much more easily remember from now on.

When the students' opinions on the positive aspects of 3D model development are examined, the students said that the current study greatly contributed to their ability to animate in their mind, which is an important sub-dimension of spatial ability. It is also considered beneficial to learn the volume concept, which is an important subject of mathematics, and that through better understanding of the design of 3D games such as Minecraft, the current study also contributes to those students who in the future may want to work within the animation profession (Brudigam \& Crawford, 2012; David, 2012; McClurg et al., 1997; Olkun, 2003; Rafi et al., 2008; Subrahmanyam \& Greenfield, 1994; Turğut, 2007). However, whilst 3D modelling is usually reserved for the domain of university engineering or technical drawing departments, the participation of secondary school students in such activities can also significantly contribute to their improved preparedness for entering higher education and for their future careers.

When the answers to the question of how to define spatial ability were directed to the students, and they were asked which skills fell within the scope of spatial ability, it was seen that the students generally described spatial ability according to the tests conducted in the current study. They also provided daily life examples such as how to stack more dishes into a dishwasher, or how to fit more corn into a pot; which demonstrates their having learnt the subject matter to a significant level.

When asked for their opinions on the use of Tinkercad, the students offered both positive and negative opinions. When their positive opinions were examined; they mentioned that Tinkercad contributed to their creativity and imagination, and it was seen as an easy-to-use and easy-to-learn design tool, that they found it fun and enjoyable to use, and that they generally liked it. These opinions show that the program level was appropriate for them, that it contributed to their skills development, and that they also had fun whilst using it. When the students' negative opinions were examined; it was seen that they found the program difficult to become accustomed to using at the beginning, and that they experienced difficulties with the camera control and the alignment of objects. However, as they became more accustomed to using the Tinkercad program, they explained that these problems lessened or were no longer considered an issue. This may have been due to their not having previously used any type of 3D design tool. The 
problem of not being able to work offline or to save progress offline -since Tinkercad only operates online- was definitely considered a restriction that the students believe the developers of Tinkercad should aim to resolve.

In the review of the literature, it was found that almost every profession uses spatial ability to some degree, and that it is a critical ability which is a contributing success factor for many professions. In the views of the participant students of the current study, they stated that this type of design study contributes to future professions such as engineering, architecture, clinical medicine, teaching, painting, and sculpture (Kurtuluş, 2011; Olkun \& Altun, 2003; Rafi et al., 2005).

It seems that whilst the applications created using Tinkercad drew certain user suggestions, mostly the suggestions the students put forward were based upon their own interests. When the students were asked for their recommendation about what could be changed if the same study were to be applied to another study group, they mentioned that in general they were satisfied with the study, and that their only recommendations were based upon their own areas of interest. It was found that the female participant students would like to work more with clothing and decorative design, whereas the male students generally wanted to transfer the exact same objects seen in real life into the 3D environment.

\section{Conclusion and Recommendations}

In the current research, the effects of the applications performed within a web-based 3D design tool, on the spatial visualisation and mental rotation abilities of secondary school students were examined. Abilities within the scope of spatial ability are dealt with as 'visualising the appearance of objects in different directions', 'rotating objects in the mind' and 'visualising the cross-section surfaces of objects'. Applications made with the web-based 3D design tool significantly increased the participant students' scores for all three abilities. From the findings reported in the experimental section, it was seen that the students who created 3D design applications made significant progress in their spatial visualisation ability. When the opinions of the students were examined, it was seen that they emphasised the study having contributed to their ability to look at an object from all directions, seeing it from a more detailed viewpoint, being able to see objects from different angles, being able to 'think in 3D', and being able to rotate new things formed through the combining of multiple objects.

When the opinions of the students were examined, it was seen that the current study contributed to their ability to rotate $3 \mathrm{D}$ objects imaginatively, to visualise objects within their minds, and to resolve questions about mental rotation much easier and faster than before. The students' opinions prove that the reasons behind the increases seen in their mental rotation post-test results can be attributed to their participation in the current study. Moreover, they indicated that the 3D design applications contributed to their ability to look at a sliced cut from the side angle when an object is cross-sectioned, to cut the objects in their minds and to predict the parts that would remain, and to then to be able to move the objects around within their own minds. 
When the limitations of the current study are examined, the current research was limited to sixth-grade students enrolled to an Information Technologies and Software course. The measurement of spatial visualisation ability was limited to the Spatial Visualisation Test, whilst the measurement of mental rotation ability was limited to the Mental Rotation Test, and the measurement of the students' ability to visualise cross-section surfaces of objects, including spatial orientation and spatial relationships, was limited to the Santa Barbara Solids Test. Since there are many different test instruments available to measure the various aspects of spatial ability, future studies could be designed to employ alternative testing instruments. The models designed in the current study were from easy to hard and conducted based on the inductive method. Alternatively, future studies could be conducted that consider different models and activities within different $3 \mathrm{D}$ design environments.

\section{References}

Baki, A., Kösa, T., \& Güven, B. (2011). A comparative study of the effects of using dynamic geometry software and physical manipulatives on the spatial visualization skills of pre-service mathematics teachers. British Journal of Educational Technology, 42(2), 291-310.

Bannatyne, A. (2003). Multiple intelligences. Bannatyne reading, writing, spelling and language program. Retrieved from http://www . bannatynereadingprogram.com/BP12MULT.htm

Basham, K. L., \& Kotrlik, J. W. (2008). The effects of 3-dimensional CADD modeling on the development of the spatial ability of technology education students. Journal of Technology Education, 20(1), 32-47.

Brudigam, K. L., \& Crawford, R. H. (2012, June). Spatial ability in high school students. Paper presented at the 119th ASEE Annual Conference and Exposition, San Antonio, TX.

Burnet, S. A., \& Lane, D. M. (1980). Effects of academic instruction on spatial visualization. Intelligence, 4(3), 233-242.

Carroll, J. B. (1993). Human cognitive abilities: A survey of factor-analytic studies. Cambridge: Cambridge University Press.

Chang, Y. (2014). 3D-CAD effects on creative design performance of different spatial abilities students. Journal of Computer Assisted Learning, 30(5), 397-407.

Cho, J. Y. (2017). An investigation of design studio performance in relation to creativity, spatial ability, and visual cognitive style. Thinking Skills and Creativity, 23, 67-78.

Clements, D. H., \& Battista, M. T. (1992). Geometry and spatial reasoning. In D. A. Grouws (Ed.), Handbook of research on mathematics teaching and learning: A project of the National Council of Teachers of Mathematics (pp. 420-464). New York, NY: Macmillan.

Cohen, C. A., \& Hegarty, M. (2007). Sources of difficulty in imagining cross sections of 3D objects. In D. S McNamara \& J. G. Trafton (Eds.), Proceedings of the $29^{\text {th }}$ Annual Cognitive Science Society (pp. 179-184). Austin, TX: Cognitive Science Society.

Cohen, C. A., \& Hegarty, M. (2008, June). Spatial visualization training using interactive animation. Paper presented at the 2008 Conference on Research and Training in Spatial Intelligence. Sponsored by National Science Foundation, Evanston, IL.

Contero, M., Company, P., Naya, F., \& Saorín, J. L. (2006). Learning support tools for developing spatial abilities in engineering design. International Journal of Engineering Education, 22(3), 470-477.

Crano, W. D., \& Johnson, C. D. (1991). Facilitating reading comprehension through spatial skills training. The Journal of Experimental Education, 59(2), 113-127.

Creswell, J. W. (2003). Research design: Qualitative, quantitative, and mixed methods approaches (2nd ed.). Thousand Oaks, CA: Sage.

David, L. T. (2012). Training effects on mental rotation, spatial orientation and spatial visualisation depending on the initial level of spatial abilities. Procedia-Social and Behavioral Sciences, 33, 328-332.

D’Oliveira, T. C. (2004). Dynamic spatial ability: An exploratory analysis and a confirmatory study. International Journal of Aviation Psychology, 14(1), 19-38.

Dorta, N., Saorín, J. L., \& Contero, M. (2008). Development of a fast remedial course to improve the spatial abilities of engineering students. Journal of Engineering Education, 97(4), 505-513. 
Ekstrom, R. B., French, J. W., Harman, H. H., \& Dermen, D. (1976). Manual for kit of factor-referenced cognitive tests. Princeton, NJ: Educational testing service.

Fleron, J. F. (2009). Google SketchUp: A powerful tool for teaching, learning and applying geometry. Westfield, MA: Westfield State College. Retrieved from http://www. westfield.ma.edu/math/prime/concrete.ideas/gsupapernctm.pdf

Gardner, H. (2011). Frames of mind: The theory of multiple intelligences. New York, NY: Basic books.

Güven, B., \& Kösa, T. (2008). The effect of dynamic geometry software on student mathematics teachers' spatial visualization skills. TOJET: The Turkish Online Journal of Educational Technology, 7(4), 100-107.

Hartman, N. W., \& Bertoline, G. R. (2005). Spatial abilities and virtual technologies: Examining the computer graphics learning environment. In E. Banissi, M. Sarfraz, J. C. Roberts, B. Loften, A. Ursyn, R. Aslak Burkhard,...Andrienko (Eds.), Proceedings of the 9th International Conference on Information Visualisation (pp. 992-997). Washington, DC: IEEE Computer Society.

ISTE. (2008). ISTE standards: Teachers. Retrieved from http://www. iste.org/standards/standards/standards-for-teachers

ISTE. (2016). ISTE standards: Students. Retrieved from http://www.iste.org/standards/standards/for-students-2016

Kakmacı, Ö. (2009). Altıncı sınıf öğrencilerinin uzamsal görselleştirme başarılarının bazı değişkenler açısından incelenmesi [Investigation of the sixth grade students' spatial visualization success in terms of some variables] (Unpublished Master's thesis). Osman Gazi Üniversitesi, Eskişehir, Turkey.

Kayhan, E. B. (2005). Investigation of high school students' spatial ability (Master's thesis). Middle East Technical University, Ankara, Turkey. Retrieved from https://etd.lib.metu.edu.tr/upload/12605771/index.pdf

Kurtuluş, A. (2011). Effect of computer-aided perspective drawings on spatial orientation and perspective drawing achievement. TOJET: The Turkish Online Journal of Educational Technology, 10(4), 138-147.

Kurtuluş, A. (2013). The effects of web-based interactive virtual tours on the development of prospective mathematics teachers' spatial ability. Computers \& Education, 63, 141-150.

La Ferla, V., Olkun, S., Akkurt, Z., Alibeyoglu, M. C., Gonulates, F. O., \& Accascina, G. (2009). An international comparison of the effect of using computer manipulatives on middle grades students' understanding of three-dimensional buildings. In Proceedings of the 9th International Conference on Technology in Mathematics Teaching. Metz, France: ICTMT.

Lin, C.-H., \& Chen, C.-M. (2016). Developing spatial visualization and mental rotation with a digital puzzle game at primary school level. Computers in Human Behavior, 57, 23-30.

Linn, M. C., \& Petersen, A. C. (1985). Emergence and characterization of sex differences in spatial abilities: A meta-analysis. Child Development, 56(6), 1479-1498

Lohman, D. F. (1993, July). Spatial ability and g. Paper presented at the First Spearman Seminar, University of Plymouth, United Kingdom.

Maier, P. H. (1998). Spatial geometry and spatial ability: how to make solid geometry solid? In E. CohorsFresenborg, K. Reiss, G. Toener, \& H. G. Weigand (Eds.), Selected Papers from Annual Conference of Didactics of Mathematics, Osnabrück (pp. 63-75). Osnabrück: FMD e.V.

McClurg, P., Lee J., Shavalier M., \& Jacobsen K. (1997). Exploring Children's Spatial Visual Thinking in an HyperGami Environment. In R. E. Griffin, J. M. Hunter, C. B. Schiffman, \& W. J. Gibbs (Eds.), VisionQuest: Journeys Toward Visual Literacy: Selected Readings (pp. 257-266). International Visual Literacy Association.

McGee, M. G. (1979). Human spatial abilities: Psychometric studies and environmental, genetic, hormonal and neurological influences. Psychological Bulletin 86(5), 889-918.

National Research Council. (2006). Learning to think spatially: GIS as a support system in the K-12 curriculum. Washington, DC: National Academic Press.

Norman, K. L. (1994). Spatial visualization - A gateway to computer-based technology. Journal of Special Education Technology, 12(3), 195-206.

Olkun, S. (2003). Making connections: Improving spatial abilities with engineering drawing activities. International Journal of Mathematics Teaching and Learning, 3(1), 1-10.

Olkun, S., \& Altun, A. (2003). İlköğretim öğrencilerinin bilgisayar deneyimleri ile uzamsal düşünme \& geometri başarıları arasındaki ilişki [The relationship between primary school students' computer experiences and spatial thinking \& geometry achievements]. TOJET: Turkish Online Journal of Educational Technology, 2(4), 86-91.

Özcan, K. V., Akbay, M., \& Karakuş, T. (2015). Üniversite öğrencilerinin oyun oynama alışkanlıklarının uzamsal becerilerine etkisi [Effects of gaming habits of university students on their spatial skills]. Kastaтопи Eğitim Dergisi, 24(1), 37-52. 
Pellegrino, J. W., Alderton, D. L., \& Shute, V. J. (1984). Understanding spatial ability. Educational Psychologist, 19(4), 239-253.

Peters, M., Laeng, B., Latham, K., Jackson, M., Zaiyouna, R., \& Richardson, C. (1995). A redrawn Vandenberg and Kuse mental rotations test-different versions and factors that affect performance. Brain and cognition, 28(1), 39-58.

Pribyl, J. R., \& Bodner, G. M. (1987). Spatial ability and its role in organic chemistry: A study of four organic courses. Journal of Research in Science Teaching, 24(3), 229-240.

Rafi, A., Anuar, K., Samad, A., Hayati, M., \& Mahadzir, M. (2005). Improving spatial ability using a Webbased Virtual Environment (WbVE). Automation in Construction, 14(6), 707-715.

Rafi, A., \& Samsudin, K. (2009). Practising mental rotation using interactive desktop mental rotation trainer (iDeMRT). British Journal of Educational Technology, 40(5), 889-900.

Rafi, A., Samsudin, K. A., \& Said, C. S. (2008). Training in spatial visualisation: The Effects of training method and gender. Educational Technology \& Society, 11(3), 127-140.

Smith, S. (1998). An introduction to geometry through shape, vision and position (Unpublished manuscript). University of Stellenbosch, Stellenbosch, South Africa.

Sorby, S. A. (1999). Developing 3-D spatial visualization skills. Engineering Design Graphics Journal, 63(2), 21-32.

Sorby, S., \& Baartmans, B. (2000). The development and assessment of a course for enhancing the 3D spatial visualization skills of first year engineering students. Journal of Engineering Education, 89(3), 301-307.

Stockdale, C., \& Possin, C. (1998). Spatial Relations and Learning. ARK Foundation, Allenmore Medical Center. New Horizons for Learning.

Subrahmanyam, K., \& Greenfield, P. M. (1994). Effect of video game practice on spatial ability in girls and boys. Journal of Applied Developmental Psychology, 15(1), 13-32.

Toptaş, V., Çelik, S., \& Karaca, E. T. (2012). Improving 8th grades spatial thinking abilities through a 3D modelling program. The Turkish Online Journal of Educational Technology, 11(2), 128-134.

Turğut, M. (2007). Illkögretim 2. kademe öğrencilerinin uzamsal yeteneklerinin incelenmesi [Investigation of 6, 7 and 8 grade students' spatial ability] (Unpublished Master's thesis). Dokuz Eylül Üniversitesi, İzmir, Turkey.

Turğut, M. (2010). Teknoloji destekli lineer cebir öğretiminin ilköğretim matematik öğretmen adaylarının uzamsal yeteneklerine etkisi [The effect of technology assisted linear algebra instruction on pre-service primary mathematics teachers' spatial ability] (Unpublished Doctoral dissertation). Dokuz Eylül Üniversitesi Eğitim Bilimleri Enstitüsü, İzmir, Turkey.

Uygan, C. (2011). Katı cisimlerin ögretiminde Google SketchUp \& somut model destekli uygulamaların ilkögretim matematik ögretmeni adaylarının uzamsal yeteneklerine etkisi [The effects of google sketchup and concrete model based applications in solids education on spatial ability of pre-service elementary mathematics teachers] (Unpublished Master's thesis). Eskişehir Osmangazi University, Eskişehir, Turkey.

Vandenberg, S., \& Kuse, A. (1978). Mental Rotation, a Group Test of Three-Dimensional Spatial Visualization. Perceptual and Motor Skills, 47(2), 599-604.

Wai, J., \& Uttal, D. H. (2018). Why Spatial Reasoning Matters for Education Policy. American Enterprise Institute. Retrieved from https://www.aei.org/wp-content/uploads/2018/10/Why-SpatialReasoning-Matters-for-Education-Policy.pdf

Winter, J. W., Lappan, G., Fitzgerald, W., \& Shroyer, J. (1989). Middle Grades Mathematics Project: Spatial Visualization. New York: Addison-Wesley.

Yıldız, B. (2009). Üç boyutlu sanal ortam ve somut materyal kullanımının uzamsal görselleştirme ve zihinsel döndürme becerilerine etkileri [The Effects of Using Three-Dimensional Virtual Environments and Concrete Manipulatives on Spatial Visualisation and Mental Rotation Abilities] (Master's thesis). Hacettepe Üniversitesi Fen Bilimleri Enstitüsü, Ankara, Turkey.

Yıldız, B., \& Tüzün, H. (2011). Üç-boyutlu sanal ortam ve somut materyal kullanımının uzamsal yeteneğe etkileri [Effects of using three-dimensional virtual environments and concrete manipulatives on spatial ability]. Hacettepe Üniversitesi Ĕ̈itim Fakültesi Dergisi, 41, 498-508.

Yurt, E., \& Sünbül, A. M. (2012). Sanal Ortam ve Somut Nesneler Kullanılarak Gerçekleştirilen Modellemeye Dayalı Etkinliklerin Uzamsal Düşünme ve Zihinsel Çevirme Becerilerine Etkisi [The Effects of ModelingBased Activities Created via Virtual Environment and Concrete Manipulatives on Spatial Thinking and Mental Rotation Abilities]. Kuram ve Uygulamada Eğitim Bilimleri, 12(3), 1975-1992.

Yüksel, N. S., \& Bülbül, A. (2014). Uzamsal Görselleştirme Üzerine Test Geliştirme Çalışması [Development of Spatial Visualization Test]. Necatibey Eğitim Fakültesi Elektronik Fen \& Matematik Eğitimi Dergisi, $8(2), 124-142$. 
H.E. Dere is an Information Technology Teacher at Bahcesehir College Ankara 50th Year Campus. She received her MS degree in the Department of Computer Education and Instructional Technologies (CEIT) from Baskent University in 2017. Her academic interest areas are instructional design, technology integration, and computer science education.

F. Kalelioglu is an Associate Professor of Computer Education and Instructional Technology at the Education Faculty, Baskent University. She graduated with a PhD in Computer Education and Instructional Technology from Ankara University in 2011. Her academic interest areas are e-learning, social media in education, instructional design, technology integration and computer science. She serves as a reviewer for several journals in the field of educational technology. She has published many national and international articles and book chapters. 